\title{
Research on Wind Turbine Converter Control Based on Resonant Sliding Film Controller
}

\author{
XU Wen-kuan*1,a, ZHANG You-peng ${ }^{1, b}$ \\ ${ }^{1}$ School of Automation and Electrical Engineering, Lanzhou Jiaotong University, Lanzhou, Gansu Province, China.
}

\begin{abstract}
A resonant sliding mode control strategy based on the resonant sliding film surface is proposed to control the turbine-side converter of the wind turbine so that the wind turbine can be connected to the grid smoothly under the condition of unbalanced grid voltage. Taking the doubly-fed asynchronous wind generator working under unbalanced grid voltage as the control object, establish its mathematical model and its generator-side converter. Taking the instantaneous power in the $\alpha \beta$ static coordinate system as the state variable of the sliding mode controller, the resonant sliding mode controller is studied, its parameters are designed, and experiments are carried out in the simulation platform MATLAB. A 1.5MW motor model was established and tested, and it was verified that the resonant sliding mode control strategy can control the grid voltage without static error and realize the smooth grid connection of wind turbines.
\end{abstract}

\section{Introduction}

Doubly-fed induction generator (DFIG) has been widely used in the wind power field due to its wide range of power control, small capacity of an ac power converter, and excellent performance in power control operation, and a lot of research has been conducted. However, when the occurrence of faults leads to unbalanced grid voltage, the electric energy generated by wind turbines will have negative effects such as voltage distortion and guttering, and cannot be directly connected to the grid [1-2].

The DFIG power generation system is shown in Fig.1[3-4]. The stator winding of the doubly-fed motor is directly connected to the power grid, and the power of the wind generator is transmitted to the power grid, and the power of the rotor winding can realize bidirectional flow. When the external voltage drops, the energy generated by the motor cannot be delivered. Part of the energy is charged to the DC side capacitor through the machine-side converter, causing the capacitor voltage to rise rapidly.

When modeling the doubly-fed wind power generation system in the existing literature, it is generally considered that the inductance and mutual inductance in the motor windings are linear, the stator winding and the rotor winding are three-phase symmetrical, and the magnetomotive force is distributed according to the sinusoidal law. As a result, there is a difference between the established model and the actual running system, and the established system parameters are not consistent with the actual values.

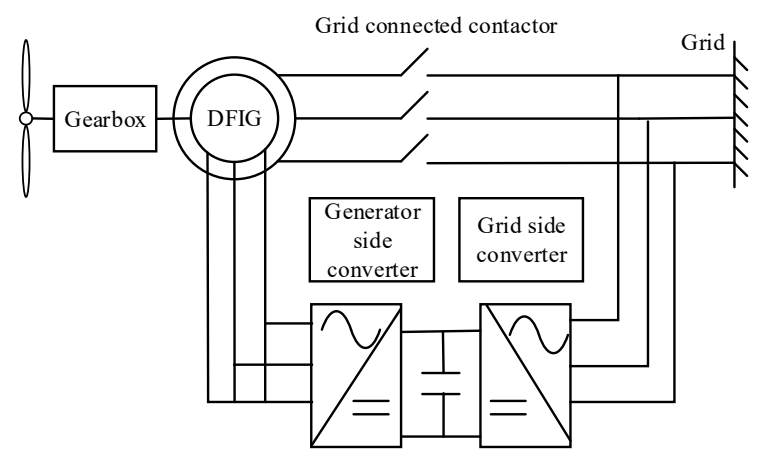

Fig.1 DFIG power generation system

When the system model parameters are inaccurate or change, the performance of the system will decrease or even become unstable. Sliding mode control, as a nonlinear control method, has the characteristics of insensitivity to model parameter errors, external disturbances, and other disturbances and simple design process. It is widely used in motor control [5-6].

There have been many studies on wind turbines operating under unbalanced voltage at home and abroad. Literature [7] proposed a sliding mode control strategy using exponential approach rate, derived the instantaneous power expansion equation, and realized the elimination of active and reactive power double frequency. Literature [8] established a converter model in a synchronous rotating coordinate system, using a feedback linearization sliding mode control method to track the DC bus voltage, and the robustness of the system was enhanced. Literature [9] introduced the fractional-order theory, analyzed the sliding mode surface and sliding mode approach rate, and adopted the

\footnotetext{
Corresponding author: ${ }^{\mathrm{a}} 1193572548 @ q q . c o m$

b2329950533@qq.com com
} 
fractional-order sliding mode control strategy, which effectively suppressed the fan jitter problem. Literature [10] established models of different wind speeds, designed a sliding mode adaptive controller, and realized real-time tracking of the generator rotor angular position, torque, and speed.

Because the vector control technology using proportional-integral relies too much on the system parameters, when the system parameters change, the closed-loop poles of the system will shift, which will lead to a decrease in control performance and even instability[11-12]. To eliminate the adverse effects of system parameters on control performance as much as possible, this paper proposes a resonant sliding mode control method based on a proportional-integral-resonant sliding mode surface. The instantaneous power in the $\alpha \beta$ static coordinate system is used as the state variable of the sliding mode controller. The mathematical model of the doubly-fed wind turbine and the generator-side converter under unbalanced grid voltage is established, and the generator-side converter voltage, current and instantaneous power in the two-phase synchronous rotating coordinate system is derived. Taking stator active power and reactive power stability without pulsation as the control goal, the stator command current value is designed to realize the smooth grid connection of the doubly-fed wind turbine under the unbalanced grid voltage [13-14].

\section{Model description}

\subsection{DFIG machine-side converter model}

The main circuit of the generator-side converter is shown in Fig.2 [15].

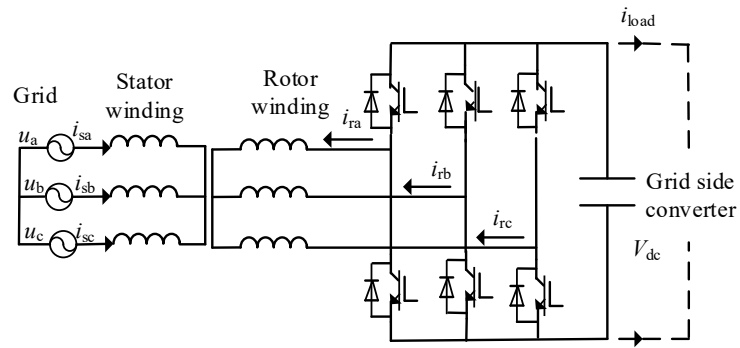

Fig.2 The main circuit of the machine side converter.

In Fig. 2 , the $i_{\mathrm{sa}} 、 i_{\mathrm{sb}} 、 i_{\mathrm{sc}}$ are the three-phase AC current of the doubly-fed motor stator. The $i_{\mathrm{ra}} 、 i_{\mathrm{rb}} 、 i_{\mathrm{rc}}$ are the three-phase AC current of machine side converter respectively .

In the three-phase static coordinate system, the three-phase stator voltage equation and the three-phase rotor voltage equation can be expressed as:

$$
\left\{\begin{array}{l}
u_{\mathrm{sa}}=R_{\mathrm{s}} i_{\mathrm{sa}}+\frac{\mathrm{d} \psi_{\mathrm{sa}}}{d t} \\
u_{\mathrm{sb}}=R_{\mathrm{s}} i_{\mathrm{sb}}+\frac{\mathrm{d} \psi_{\mathrm{sb}}}{d t} \\
u_{\mathrm{sc}}=R_{\mathrm{s}} i_{\mathrm{sc}}+\frac{\mathrm{d} \psi_{\mathrm{sc}}}{d t}
\end{array}\right.
$$

$$
\left\{\begin{array}{l}
u_{\mathrm{ra}}=R_{\mathrm{r}} i_{\mathrm{ra}}+\frac{\mathrm{d} \psi_{\mathrm{ra}}}{d t} \\
u_{\mathrm{rb}}=R_{\mathrm{r}} i_{\mathrm{rb}}+\frac{\mathrm{d} \psi_{\mathrm{rb}}}{d t} \\
u_{\mathrm{rc}}=R_{\mathrm{r}} i_{\mathrm{rc}}+\frac{\mathrm{d} \psi_{\mathrm{rc}}}{d t}
\end{array}\right.
$$

The $u_{\mathrm{sa}}, u_{\mathrm{sb}}, u_{\mathrm{sc}}$ are the instantaneous phase of the stator voltage, $u_{\mathrm{ra}}, u_{\mathrm{rb}}, u_{\mathrm{rc}}$ are rotor instantaneous phase voltage, $R_{\mathrm{S}}$ and $R_{\mathrm{r}}$ are the stators winding resistance, $\psi_{\mathrm{sa}}$, $\psi_{\mathrm{sb}}, \psi_{\mathrm{sc}}, \psi_{\mathrm{ra}}, \psi_{\mathrm{rb}}, \psi_{\mathrm{rc}}$ are stator winding of each phase flux.

By means of the transformation matrix from the three-phase static coordinate system to the two-phase static coordinate system, the stator voltage equation in the static coordinate system is:

$$
\left\{\begin{array}{l}
U_{s \alpha}=R_{\mathrm{s}} I_{\mathrm{s} \alpha}+\frac{\mathrm{d} \psi_{\mathrm{s} \alpha}}{d t} \\
U_{s \beta}=R_{\mathrm{s}} I_{s \beta}+\frac{\mathrm{d} \psi_{s \beta}}{d t}
\end{array}\right.
$$

The rotor voltage equation is:

$$
U_{\mathrm{r} \alpha \beta}=R_{\mathrm{r}} I_{\mathrm{r} \alpha \beta}+\frac{\mathrm{d} \psi_{\mathrm{r} \alpha \beta}}{d t}-j \omega_{\mathrm{r}} \psi_{\mathrm{r} \alpha \beta}
$$

$U_{\mathrm{r} \alpha \beta}=u_{\mathrm{r} \alpha}+j u_{\mathrm{r} \beta}$, the $u_{\mathrm{r} \alpha}, u_{\mathrm{r} \beta}$ are rotor voltage in the two-phase static coordinate system axis component $\alpha$ and $\beta$. $I_{\mathrm{r} \alpha \beta}=i_{\mathrm{r} \alpha}+j i_{\mathrm{r} \beta}, i_{\mathrm{r} \alpha}, i_{\mathrm{r} \beta}$ are the $\alpha$ and $\beta$ axis component of the rotor current in the two-phase static coordinate system. $\psi_{\mathrm{r} \alpha \beta}=\psi_{\mathrm{r} \alpha}+j \psi_{\mathrm{r} \beta}, \psi_{\mathrm{r} \alpha}, \psi_{\mathrm{r} \beta}$ are the $\alpha$ and $\beta$ axis components of a rotor flux chain in a two-phase static coordinate system.

The instantaneous active and reactive power equations of the doubly-fed asynchronous wind generator are:

$$
\left\{\begin{array}{l}
P_{\mathrm{s}}=-1.5\left(u_{\mathrm{s} \alpha} i_{\mathrm{s} \alpha}+u_{\mathrm{s} \beta} i_{\mathrm{s} \beta}\right) \\
Q_{\mathrm{s}}=-1.5\left(u_{\mathrm{s} \beta} i_{\mathrm{s} \alpha}-u_{\mathrm{s} \alpha} i_{\mathrm{s} \beta}\right)
\end{array}\right.
$$

The control variable of the sliding mode controller is designed with the stator active power and reactive power stable without pulsation as the control objective. The control variable is the reference value of the stator active power and reactive power.

Under the unbalanced grid voltage, the average active and reactive power output by the doubly-fed motor can be considered as the result of the positive sequence fundamental wave voltage $U_{\alpha \beta+}$ and the stator sinusoidal current $i_{\text {r } \alpha \beta+}^{*}, U_{\alpha \beta+}$ can be obtained by the "quarter cycle delay" method:

$$
\begin{gathered}
u_{\alpha \beta+}=\frac{1}{2}\left(u_{\alpha \beta} \pm u_{\beta \alpha}^{\prime}\right) \\
\left\{\begin{array}{l}
P_{\mathrm{s}}^{*}=-1.5\left(u_{\mathrm{s} \alpha+} i_{\mathrm{s} \alpha+}^{*}+u_{\mathrm{s} \beta+} i_{\mathrm{s} \beta+}^{*}\right) \\
Q_{\mathrm{s}}^{*}=-1.5\left(u_{\mathrm{s} \beta+} i_{\mathrm{s} \alpha+}^{*}-u_{\mathrm{s} \alpha+} i_{\mathrm{s} \beta+}^{*}\right)
\end{array}\right.
\end{gathered}
$$

In the formula, $P^{*} S$ and $Q^{*} S$ are direct current, which is the given value of average active and reactive power. The current reference value under the control target can be solved: 


$$
\left\{\begin{array}{l}
i_{\mathrm{s} \alpha+}^{*}=\frac{-1.5\left(u_{\mathrm{s} \alpha+} P_{\mathrm{s}}^{*}+u_{\mathrm{s} \beta+} Q_{\mathrm{s}}^{*}\right)}{u_{\mathrm{s} \alpha+}^{2}+u_{\mathrm{s} \beta+}^{2}} \\
i_{\mathrm{s} \beta+}^{*}=\frac{-1.5\left(u_{\mathrm{s} \alpha+} P_{\mathrm{s}}^{*}-u_{\mathrm{s} \beta+} Q_{\mathrm{s}}^{*}\right)}{u_{\mathrm{s} \alpha+}^{2}+u_{\mathrm{s} \beta+}^{2}}
\end{array}\right.
$$

By substituting the current reference value back into Equation (6), the reference value of work and reactive power can be obtained:

$$
\left\{\begin{array}{l}
P_{\text {sref }}=-1.5\left(u_{\mathrm{s} \alpha} i_{\mathrm{s} \alpha+}^{*}+u_{\mathrm{s} \beta} i_{\mathrm{s} \beta+}^{*}\right) \\
Q_{\text {sref }}=-1.5\left(u_{\mathrm{s} \beta} i_{\mathrm{s} \alpha+}^{*}-u_{\mathrm{s} \alpha} i_{\mathrm{s} \beta+}^{*}\right)
\end{array}\right.
$$

In this way, the negative sequence and harmonic components of the stator current of the doubly-fed wind generator can be eliminated.

\subsection{Resonant sliding mode controller}

Considering that the parameters of the established system model are uncertain and will change during operation, and the robustness of the system must be considered, a proportional-integral resonance sliding mode control strategy based on a sliding mode controller is adopted. Sliding mode control has insensitivity to system parameter errors and changes and excellent dynamic response. Recently, it has been widely used in no-load grid connection, low voltage ride-through, and direct torque control of wind power generation. Integral sliding mode control can suppress the fluctuation of reactive power and electromagnetic torque under unbalanced grid voltage through the integral controller, and realize its stable output. But for higher frequency disturbances, integral sliding mode control can only reduce the error and can achieve no static error control. In order to achieve no static error control, the corresponding resonance term can be added to the sliding surface equation to make it the sum of the state variable, integral term, and resonance term of the sliding mode control controller[16-17]. The resonant sliding mode control block diagram of the DFIG generator-side converter is shown in Fig.3.

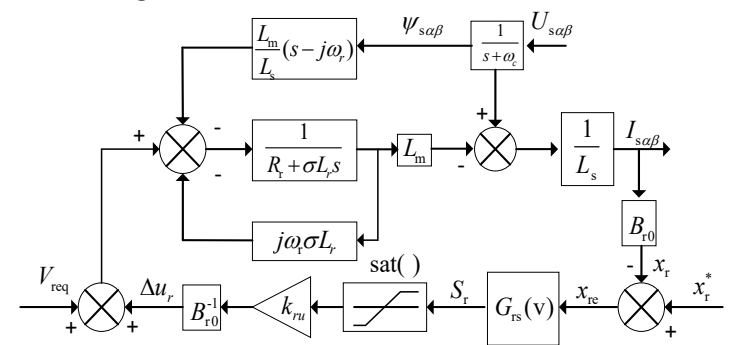

Fig.3 Machine-side converter resonant sliding mode control block diagram.

The sliding surface equation of the doubly-fed wind generator is:

$$
S_{\mathrm{r}}(s)=\left[S_{\mathrm{ps}}(s) S_{\mathrm{ps}}(s)\right]^{T}=x_{\mathrm{re}}(s) G_{\mathrm{rs}}(s)
$$

$$
\begin{aligned}
G_{\mathrm{rs}}(s)= & 1+\frac{k_{\mathrm{rs}}}{s}+\frac{s k_{\mathrm{rr} 2}}{s^{2}+2 \omega_{\mathrm{rc} 2} s+(2 \omega)^{2}} \\
& +\frac{s k_{\mathrm{rr} 6}}{s^{2}+2 \omega_{\mathrm{rc} 6} s+(6 \omega)^{2}}
\end{aligned}
$$

Where $G_{\mathrm{rs}}(\mathrm{s})$ is the transfer function of the sliding surface of the sliding mode control system of the generator-side converter. $K_{\mathrm{rs}}$ is the sliding area coefficient. $K_{\text {rr2 }}$ and $K_{\text {rr6 }}$ corresponding to the sliding surface resonance coefficient of double frequency and sixth frequency. $\omega_{\text {rc2 }}$ and $\omega_{\text {rc6 }}$ are used to adjust the cut-off frequency of the two-fold and six-fold resonance terms.

Taking the difference between the stator active power and reactive power of the doubly-fed wind generator and its reference value as the control variable of the machine-side resonant sliding mode controller, the relationship between the disturbance difference and the power difference is obtained as:

$$
\begin{gathered}
x_{\mathrm{re}}=x_{\mathrm{r}}^{*}-x_{\mathrm{r}} \\
s G_{\mathrm{rs}}(s) x_{\mathrm{re}}=-h_{\mathrm{r}}-k_{\mathrm{ru}} \operatorname{sat}\left[G_{\mathrm{rs}}(s) x_{\mathrm{re}}\right]
\end{gathered}
$$

Using the analysis method of the phase plane diagram, the phase plane diagram of the power error of the generator-side converter resonant sliding mode control system under different disturbances $h_{\mathrm{r}}$ can be drawn, as shown in Fig.4:

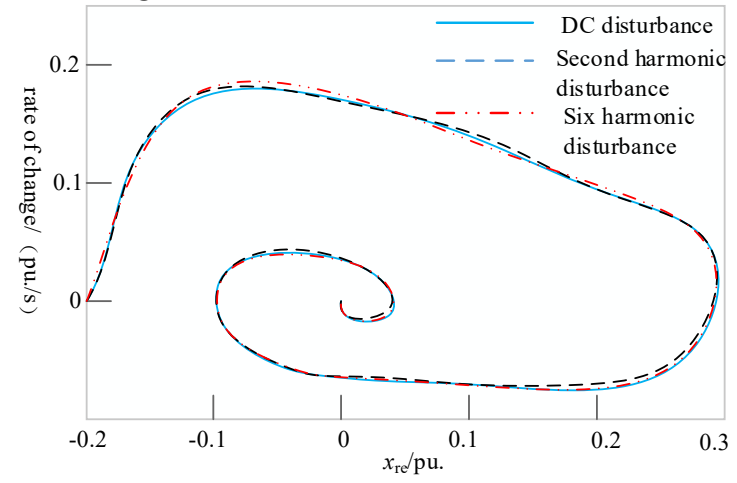

Fig.4 Phase plan of the power error under disturbance $h_{\mathrm{r}}$.

It can be seen from Fig. 4 that whether it is DC disturbance, 2 times frequency $\mathrm{AC}$ disturbance, or 6 times frequency $\mathrm{AC}$ disturbance, the tracking error tends to zero under resonant sliding mode control. It shows that the resonant sliding mode control strategy has a very strong ability to suppress the harmonic interference generated by the unbalanced grid voltage [18].

Using the analysis method of the phase plane diagram, the phase plane diagram of the power reference value and power error of the resonant sliding mode control system of the generator-side converter can be drawn, as shown in Fig.5: 


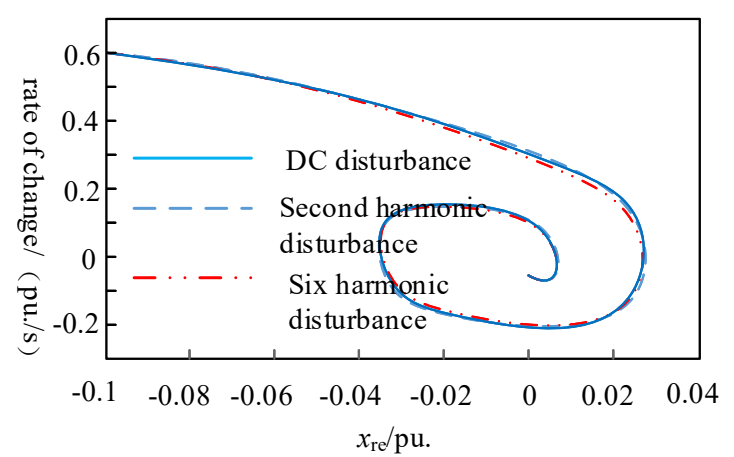

Fig.5 Phase plan of power error under reference power.

When the resonant sliding mode control strategy is adopted, no static error control can be achieved for the direct current and the corresponding frequency of the alternating current [19], as shown in Fig. 5.

\section{System simulation experiment}

The DFIG model parameters established are shown in Table 1 .

\begin{tabular}{cccc} 
& Table 1 & DFIG parameter & \\
\hline Parameters & Value & Parameters & Value \\
\hline $\begin{array}{c}\text { Rated power } \\
(\mathrm{MW})\end{array}$ & 1.5 & Frequency $(\mathrm{Hz})$ & 50 \\
$\begin{array}{c}\text { Stator resistance } \\
(\Omega)\end{array}$ & 0.025 & Rotor resistance $(\Omega)$ & 0.013 \\
$\begin{array}{c}\text { Mutual } \\
\text { inductance }(\mathrm{H})\end{array}$ & 0.007 & Leakage inductance $(\mathrm{H})$ & 0.002 \\
\hline
\end{tabular}

Fig. 6 shows the waveform diagram of phase A with a $40 \%$ drop in grid voltage, while phases $\mathrm{B}$ and $\mathrm{C}$ remain unchanged. Fig. 7 is the voltage waveform diagram of the DFIG generator-side converter after adopting the resonant sliding mode controller. By comparison, it can be concluded that the sliding mode control strategy can effectively control the wind turbine side converter voltage to accurately change with the change of the grid voltage, and it can achieve no static difference control for both the DC quantity and the corresponding frequency AC quantity.

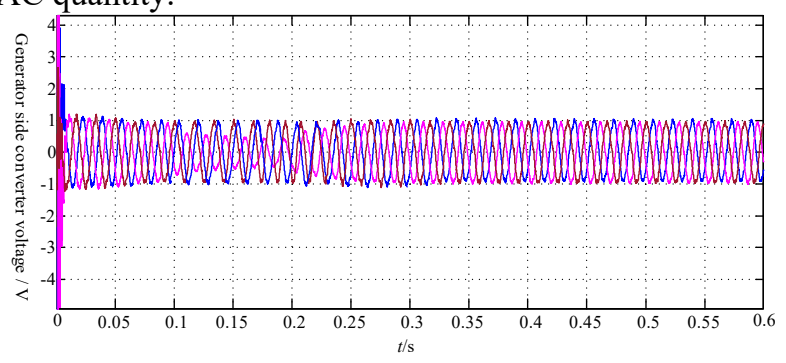

Fig.6. Grid voltage.

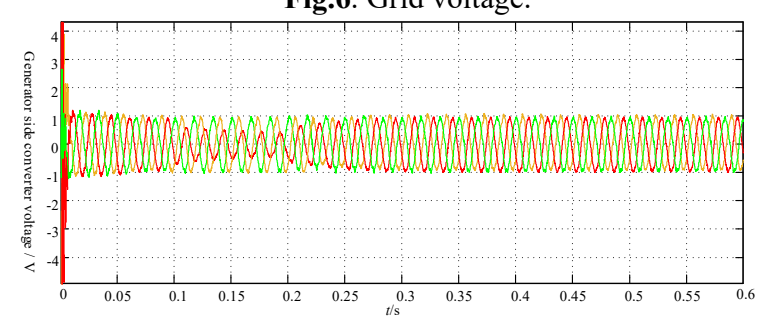

Fig.7 The voltage of machine side converter.
Fig.8 shows the three-phase current waveform of the stator. Although the grid voltage is unbalanced due to the fault, under the resonant synovial control strategy, the three-phase sinusoid of the stator output current of the wind generator can still be unaffected by the variation of the grid voltage.

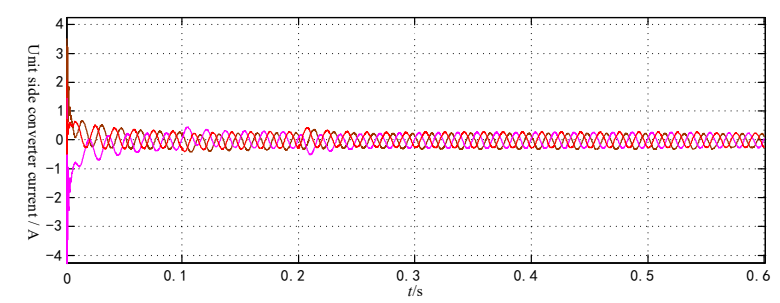

Fig.8 The current of machine side converter.

Fig. 9 shows the active power of the wind turbine generator-side converter, and Fig.10 shows the reactive power of the wind turbine generator-side converter. Since the control variable of the generator-side resonant sliding mode controller is the error between the generator power and its reference value, the control objective is that the stator active power and reactive power are stable and without pulsation. It can be seen from the figure that the final active power is $1.5 \mathrm{MW}$ and the reactive power is 0 . The results show that the resonant sliding mode control strategy can ensure the effectiveness of the stator active power and reactive power output.

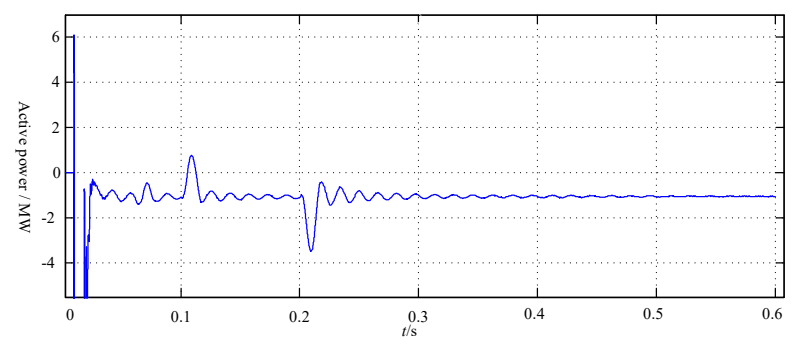

Fig.9 Machine-side converter active power.

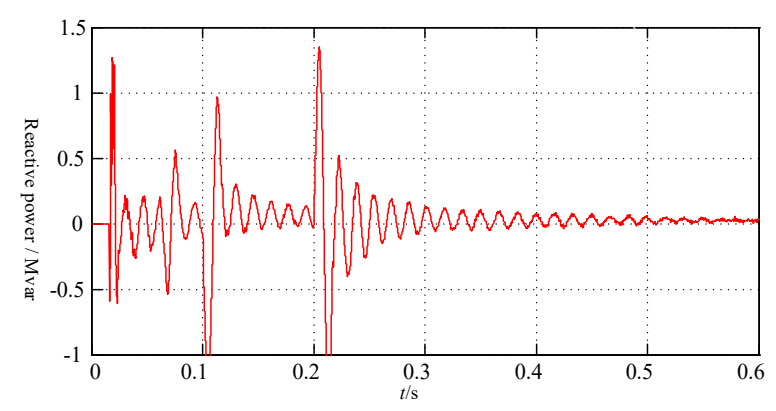

Fig.10 Machine-side converter reactive power.

\section{Conclusion}

In this paper, the operation status of doubly-fed wind turbine under unbalanced grid voltage is studied, the mathematical model of doubly-fed wind turbine and its side converter is established, and the corresponding control relation is deduced. The control target is the stator three-phase current sinusoidal balance without harmonics, and the control quantity is the error between the stator active power, reactive power, and reference 
value. The proportional integral resonant sliding mode control strategy is adopted to adjust the side converter of the DFIG machine to realize its smooth grid connection in an unbalanced grid environment.

Through the simulation experiment in SIMULINK, through the grid voltage and the comparison of machine side converter output voltage, and the stator active and reactive power output waveform proved in unbalanced power grid voltage. A control strategy based on the proportional-integral resonant sliding mode controller can accurately control the generator-side converter so that the output power is three-phase sinusoidal balance without distortion.

\section{Acknowledgments}

This paper is one of the phased achievements of NSFC regional fund project "Study on pollution flashover characteristics and on-line monitoring technology of overhead contact line insulators for electrified railway in the dust area of Western China"(51567014).

\section{References}

1. National People's Congress. Renewable energy law of the people's Republic of China[EB/OL]. http://www.npc.gov.cn.

2. State Council. 12th Five Year Plan for energy conservation and emission reduction[EB/OL]. http://www.npc.gov.cn/zwgk/2012-08/21/content_2 207867.htm

3. ZHANG T.H. Research on Maximum Wind Power Tracking Control of Variable Speed Constant Frequency Doubly-Fed Wind Power Generation System[D]. Shenyang: Shenyang University of Technology,2018.

4. DENG S.X, ZHANG X.M, LIU H,et al. Quantitative Evaluation of Low Voltage Ride-through Control Strategies for Doubly-fed Induction Generator[J]. Automation of Electric Power Systems, 2018,42(21):28-35.

5. GUAN P, LI J. Direct Power Control Based on Fractional Order Sliding Mode for Wind Generator $[\mathrm{J}]$. Electric Machines Control Application,2018,45(09):97-102.

6. XIE Z, LI M.J, ZHANG X, YANG S.Y. Harmonic-voltage Suppress Strategy of Doubly-fed Induction Generators Based on Voltage Source Droop Grid-connected Output[J]. Proceedings of the CSEE,2018,38(17):5228-5237+5320.

7. HAN X, CAN X. Sliding-Mode Control of Current for Wind Power Grid-Connected Converter Under Unbalanced Grid Voltage[J]. Journal of Shanghai Jiaotong University,2018,52(09):1065-1071.

8. ZHANG W.B, WANG H, BAI R,LI S,HUANG Y. Research on Dual PWM Converters Based on Feedback Linear and Sliding Mode Control[J]. Journal of micro and special motors,2018,46(08): 57-61.
9. LI Z.M, LIU B. Fractional-order sliding mode control strategy for grid-connected inverter with LCL filter[J].Information Technology,2018(09): 28-32.

10. ZHANG K.M, SHI H.J, GUO T. Maximum Power Control of Permanent Magnet Synchronous Wind Power Generation System Based on Sliding-mode Adaptive Control[J]. Proceedings of the CSU-EPSA, 2019,31(07):143-150.

11. TAN Z.K, XU Y.T, XIAO Y, LV Q. S. A scheme of low harmonic current suppression for doubly-fed induction generator[J]. Electrical Measurement \& Instrumentation,2018,55(18):64-69+81.

12. WANG A.M, HUANG P.D, DONG S.H. Research on application of novel co-simulation in doubly fed induction generator under unbalanced fault[J]. Electrical Measurement \& Instrumentation, 2018, 55(04):124-129.

13. BU S.P, CHENG L, LIU H. Research on power control strategy of wind farm $[\mathrm{J}]$. Electrical Measurement \& Instrumentation,2016,53(14):5155.

14. HAN X.S, LIU Q.H. The simplification and analysis of DFIG converter model[J]. Electrical Measurement \& Instrumentation,2015,52(23):2328.

15. ZHANG C.J, WANG Y, YANG H.J, CHAI X.H. Research on Torque Pulsation Suppression of Doubly-fed Induction Generator Under Grid Voltage Unbalance[J].ACTA ENERGIAE SOLARIS SINICA,2013,34(06):924-932.

16. ZHANG K.M, SHI H.J, GUO T. Maximum Power Control of Permanent Magnet Synchronous Wind Power Generation System Based on Sliding-mode Adaptive Control[J]. Proceedings of the CSU-EPSA, 2019,31(07):143-150.

17. FANG F, LI Y. Integrated Sliding-Mode Current Control Strategy for Energy-Stored Quasi-Z-Source Inverter[J].Power System Technology, 2018,42(09): 2967-2975.

18. ZHANG L.W, WEI W, ZHANG C, et al. Study on Permanent Magnet Synchronous Motor Servo System Based on Total Sliding Mode Control Approach with Nonlinear Integrator[J].Transactions of China Electrotechnical Society,2018,33(16): 3917-3924.

19. LIU S, LIU Z.G, WANG Y.Q,GENG Z.Z. A Novel Approach to Low Frequency Oscillation Suppression of Traction Network Voltage Based on SMC[J].Power System Technology,2018,42(09): 2999-3006. 